\title{
QUASI-PERIODIC SOLUTIONS OF NONLINEAR DIFFERENTIAL EQUATIONS VIA THE FLOQUET-LIN THEORY
}

\section{J. Ben SLimene And J. Blot}

Abstract. We use a Floquet theory for quasi-periodic linear ordinary differential equations due to Zhensheng Lin to obtain results on the quasi-periodic solutions of quasi-periodic nonlinear ordinary differential equations. First we obtain an existence result, secondly we obtain a result on the continuous dependence by using a parametrized fixed point theorem, and thirdly we obtain a local result on the differentiable dependence by using an implicit function theorem in function spaces.

Mathematics subject classification (2010): 34C27, 34C15, 34D08. theorem.

Keywords and phrases: quasi-periodic solutions, Floquet theory, fixed-point theorem, implicit function

\section{REFERENCES}

[1] J. Blot, P. Cieutat And J. MAWhin, Almost periodic oscillations of monotone second order systems, Adv. Differential Equations, 2, 5 (1997), 693-714.

[2] J. Blot, P. Cieutat, G.M. N'GuÉrékata And D. Pennequin, Superposition operators between various almost periodic function spaces and applications, Commun. Math. Anal., 6, 1 (2009), 12-70.

[3] J. Blot And D. Pennequin, Spaces of Quasi-Periodic Functions and Oscillations in Differential Equations, Acta Appl. Math., 65 (2001), 83-113.

[4] H. Cartan, Cours de calcul différentiel, Hermann, Paris, 1967.

[5] C. Corduneanu, Almost Periodic Functions, Second English Edition, Chelsea, New York 1989.

[6] A. M. Fink, Almost Periodic Differential Equations, Lect. Notes Math. 377, Springer-Verlag, Berlin, 1974.

[7] G. M. N'GUÉRÉKATA, Topics in almost automorphy, Springer, New York, 2005.

[8] Z. Lin, The Floquet theory for quasi-periodic linear systems, Appl. Math. Mech., Eng. Ed. 3, (1982), 365-381.

[9] Z. Lin, Theory of linear systems, Ann. Differ. Eq., 6, 2 (1990), 153-215.

[10] Z. Lin AND Y. X. Lin, Linear Systems, Exponential Dichotomy, and Structure of Sets of Hyperbolic Points, World Scientific, Singapore, 2000.

[11] M. Roseau, Vibrations non linéaires et théorie de la stabilité, Springer-Verlag, Berlin, 1966.

[12] A. M. Samoilenko, Elements of the Mathematical Theory of Multi-Frequency Oscillations, English Edition, Kluwer Academic Publishers, Dordrecht, 1991.

[13] T. Yoshizawa, Stability Theory and the Existence of Periodic Solutions and Almost Periodic Solutions, Springer-Verlag, New York, 1975.

[14] L. Schwartz, Cours d'analyse, tome 1, Hermann, Paris, 1981. 